\title{
Discussion: Treatment of risk and reliability in the Eurocodes
}

\section{T. Vrouwenvelder}

\section{Contribution by A. N. Beal}

The theoretical basis of the Eurocode partial factor system is not as secure as claimed and, in some cases, it can produce very questionable results from an engineering point of view. ${ }^{18}$ Particular problems are listed below.

In the Eurocodes, in general all 'permanent' loads are allocated a low partial factor (normally 1.35) and all 'variable' loads are allocated a higher factor (normally $1 \cdot 5$ ). It is, however, a mistake to assume that all 'permanent' loads are predictable and all 'variable' loads are unpredictable. Some 'permanent' loads such as earth pressure or the weight of finishes are difficult to predict accurately, yet the weight of water in a tank, which is 'variable', can easily be calculated to an accuracy of $1 \%$. Also the nature and significance of different types of load needs to be considered: the loading from a crowd of people standing on a floor should not be allocated the same safety factor as a $3 \mathrm{~s}$ wind gust with a 1/50 probability of occurrence.

Second, published probability analyses often make crude and simplistic assumptions about how different types of loading vary and material strengths are often assumed to be ' $5 \%$ probability of failure' values, even though current material specifications generally do not produce this result.

Third, Turkstra's 'law' (in a load combination, only one variable load is taken at its full value and all others are reduced to 'combination' values) may seem reasonable in principle but the rigid application of it in current Eurocodes can give strange results. For example, it means that a structure that resists wind loads only (such as a signpost) is given a higher factor of safety than one which supports both imposed loads and wind loads (such as a house, office or public building). Also it implies that the design loading on a structure can be reduced simply by dividing it up into several parts with different labels: for example, if ordinary 'imposed load' on a floor is divided up into , for example, 'people', 'furniture' and 'equipment', then under Turkstra's law only one of these would need to be considered at its maximum value, and the other two would be at reduced 'combination' values.

The effects of this can be seen when Eurocode partial factors are multiplied together in a design. The average safety factor (based on steel strength) in Eurocode 2 for a structure supporting dead load + live load (DL+LL) (50/50) is $1 \cdot 64$, yet for a structure subjected to only wind load (WL) it is increased to $1 \cdot 72$. For an earth-retaining wall the safety factor is 1.55 but for the wall of a water tank is 1.72 required. For overturning stability, the Eurocode 2 safety factor is 1.22 (DL only), $1 \cdot 44$ (DL+LL), 1.31 (DL+LL+WL) and 1.67 (WL only).

Many of these variations are inconsistent with past practice and they do not seem right from an engineering point of view. Taken together, they suggest that, despite the efforts of the theoreticians involved, there are problems with the Eurocode partial safety factor system and it is not delivering the consistent, rational results that are required.

\section{Author's reply}

In his first comment, the contributor touches on an important issue. Eurocode 1990 recommends a factor of 1.35 for permanent loads and 1.50 for most variable loads. The author agrees that this is a far-reaching simplification, certainly not correct in all cases. One should, however, keep in mind that these values do not form an intrinsic part of the code system, but are recommended values that can be ignored at the national level. Each European Committee for Standardization (Comité Européen de Normalisation (CEN)) member state has the right to prescribe values that correspond better to a more realistically estimated scatter. Some countries in fact do.

The second point concerns the crudeness of assumptions done. It is the author's opinion that wherever this is true, it should be indicated. Where relevant data are available, they should be used to adjust the assumptions. This possibility may be considered as a strong point of the procedure, not as a weak point. Note, by the way, that not only uncertainties in loads and material properties should be considered, but also schematisations and uncertainties in modelling.

The third point misses the fundamental objective of a probability-based design. In probabilistic design, load factors are selected in such a way that they lead to a more or less uniform probability of failure (or reliability index) and not to a uniform average safety factor.

\section{REFERENCE}

18. BEAL A. N. Factors of ignorance? The Structural Engineer, 2001, 79, No. 20, 116-117. 